\title{
EDMUND HUSSERL,
}

\section{LA IDEA DE LA FENOMENOLOGÍA}

Trad. de Jesús Adrián Escudero, Barcelona, Herder, 2012, 173 PP.

\author{
por Ricardo Mendoza Canales
}

La idea de la fenomenología recoge las cinco lecciones que Edmund Husserl dictó en la Universidad de Gotinga, entre el 26 de abril y el 2 de mayo de 1907, como introducción al curso del semestre de verano dedicado a La cosa y el espacio (Ding und Raum, Husserliana XVI). La importancia histórica de estas lecciones radica en que en ellas se explica por primera vez el método de la reducción trascendental o epoché, que Husserl comenzó a elaborar tras reconocer ciertas limitaciones metodológicas durante sus lecciones de 1905 para abordar el análisis de la conciencia interna del tiempo. No obstante, aquí se hallan ya formulados también, con mayor o menor distinción, los tres grandes principios metodológicos que Husserl estableció como fundamentos y que guiarán toda su investigación posterior: (1) la exigencia intuicionista del retorno "a las cosas mismas" (ya expuesta en las Logische Untersuchungen); (2) una primera elaboración de lo que en Ideen I denominará "el principio de todos los principios" (toda intuición en que se da algo es originariamente un fundamento de derecho del conocimiento, y que todo lo que se nos brinda en la intuición hay que tomarlo como simplemente como se da, pero también solo dentro de los límites en que se da); y, finalmente, (3) el método de la reducción fenomenológica.

Desde la primera lección, Husserl establece con claridad la importancia que tiene para el conocimiento la distinción entre ciencia natural y ciencia filosófica, dado que los 
modos o actitudes intelectuales en los que aquél se fundamenta (la actitud intelectual natural y la actitud intelectual filosófica, respectivamente), condicionan no solo la captación del objeto de la investigación, sino, principalmente, el modo como se capta dicho objeto. Cuando se desplaza la pregunta del "¿qué conozco?" al "¿cómo es que alcanzo a conocer eso que conozco?", la insuficiencia de la actitud natural se revela, pues no hay respuesta satisfactoria que no se fundamente en una vivencia subjetiva. El proyecto husserliano de fundar una teoría del conocimiento como crítica del conocimiento natural consistirá en mostrar "el sentido de la esencia de la objetualidad cognoscible" (81) y, por tanto, en entrever las estructuras fundamentales de la objetualidad en general; es decir, constituir una ciencia del ser en sentido absoluto (82).

Esta crítica del conocimiento debe comenzar por un "índice de dubitabilidad" (87) al mundo entero; tanto a la naturaleza física como psíquica y, por último, al propio yo. A este punto Husserl dedica la segunda lección, donde introduce por primera vez la epoché como práctica de suspensión del sentido, aunque sin que ello comporte de ninguna manera la negación de su existencia (90). Tras la reducción, el dato (la cogitatio) será un modo del ser que se nos manifiesta, cuya esencia intuimos a partir de la captación de una vivencia. Su sentido no reside en el objeto exterior percibido, esto es, como trascendencia para el sujeto cognoscente, sino en la constitución de dicho objeto como cogitatio del propio sujeto, es decir, como inmanencia.

Para Husserl, entonces, cualquier intento de establecer un juicio sobre la base de un acto intelectual trascendentemente dirigido mediante la inferencia y deducción conlleva necesariamente a caer en una metábasis eis állo génos: el planteamiento y aplicación de proposiciones lógicas de un género concreto a otro género diferente. Es imperativo recurrir a la epoché a fin de suspender cualquier trascendencia anterior a la vivencia misma del objeto que posea carácter apriorístico, evitando así condicionar y limitar el acto de intuición (99).

La reducción fenomenológica ha confiado un terreno seguro desde donde iniciar la exploración de la esencia del conocimiento, que proseguirá a lo largo de la tercera lección. Tras la epoché se posee la certeza de la validez de la esfera de las 
cogitationes (los datos absolutos, de los que tenemos certeza gracias a la indubitabilidad de la intuición del objeto). Pero hace falta aún distinguir entre el fenómeno puro en el sentido fenomenológico y el fenómeno psicológico, el objeto de la psicología como ciencia natural. El fenómeno psicológico resulta de la atención dirigida por el sujeto hacia la sensación que experimenta como vivencia: es una percepción sentida como un hecho y el contenido manifiesto de esta sensación se halla determinado por la duración de dicha vivencia; es decir, será una vivencia inscrita en una concepción subjetiva del tiempo, mesurable empíricamente. Sin embargo, si el propósito es establecer una crítica de la razón teorética (106), ¿cómo probar entonces la validez "objetiva" de tales cogitationes si solo poseen verdad "subjetiva"? ¿Cómo establecer tales juicios sin caer nuevamente en la atribución de un sentido trascendente? El punto de partida deberá radicar, según Husserl, en la certeza indubitable de las cogitatio: la fenomenología deberá trabajar únicamente sobre la base de lo $a b$ solutamente evidente (109), aquello que se da como autodonación, es decir, aquello que en la intuición (aprehensión) del objeto este "algo" mentado remita a un dato de sí mismo y no a nada que, a fin de cumplimentar un sentido, le venga de fuera de él. Solo así se asegura la posibilidad de un conocimiento eidético, de esencias universales (111).

Los objetos de la experiencia fenomenológica son, tras la epoché, aprehendidos como autodonaciones, es decir, lo inmanente ingrediente (Reel) del acto de conocimiento. Sabemos que no brotan en la conciencia del sujeto por sí solas, sino que son el efecto de una vivencia experimentada. Cabe por tanto preguntarse por la referencia de dichas cogitationes, es decir, cuál es el contenido de dichos fenómenos: la relación entre el dato inmediato (Gegebenheit) y su correspondiente objetualidad (Gegebenstäntlichkeit), que será la materia abordada en la cuarta lección.

Para Husserl, si es posible alcanzar el conocimiento de la esencia de un objeto particular es porque, con la reducción fenomenológica, lo que se capta de la cogitatio será su ingrediente inmanente en tanto que manifestación absoluta del fenómeno aprehendido; es decir, no captamos más que lo que el objeto es en tanto que evidencia. El carácter intencional del fenómeno nos revela 
que la donación del objeto intuido contiene y refiere un sentido; es decir, revela la constitución correlativa del objeto. Llegado a este punto, debe evitarse, por un lado, confundir este objeto con un objeto "real" exterior, concreto, particular, sensible, pues se hallan en distintos órdenes de realidad; $y$, por otro lado, considerar la autodonación como el punto final de un acto de conocimiento solo porque su certeza esté garantizada por el método de la reducción y el descubrimiento de la esfera de la inmanencia ingrediente. De ser así, el acto del conocimiento quedaría encapsulado en el solipsismo, pues le atribuye a la conciencia la capacidad, a partir del dato ingrediente, de tener evidencia de lo universal (122); idea bastante alejada al planteamiento husserliano.

Ahora bien, si los datos obtenidos tras la reducción fenomenológica han de ser considerados objetivos, ¿poseen la misma validez las esencias de esos datos cuando son sensiblemente percibidos y cuando son producto de la fantasía? En la lección quinta, Husserl desarrolla un minucioso análisis que intenta abordar esta cuestión. El primer paso, sostiene, es reconocer, mediante la reducción, el ser temporal del fenómeno: la percepción del tiempo es captada como donación. Este ser temporal "[s]e presenta en el fenómeno y está en él dado como 'siendo' evidentemente" (126).

La donación de esencias no es captación "unidireccional", sino revelación constituyente: el dato absoluto no solo extrae de él un universal, sino que también universaliza el objeto que aparece. De allí que tanto la percepción "real" como la fantasía y la rememoración puedan servir como base para donación de esencias, pues porque todas ellas proporcionan posibilidades de ser aprehendidas puramente y se extraen universales de estos actos: la posición de existencia del objeto resulta irrelevante para la captación de la esencia (como autodonación). Tanto en la percepción, como en la rememoración o fantasía, hay la vivencia de un fenómeno, existente o no-existente, del cual se extrae su esencia. Lo que resulta indubitable es que ambas poseen realidad. Si los modos de ser expresan al ser, entonces los contenidos ingredientes revelados en la cogitatio no habitan en la inmanencia, como si estuvieran dormidos a la espera de ser activados: no descubre nada que ya sea inherente a ella. Al enfatizar el carácter experiencial de la constitución, se abre acceso tanto a una 
intuición del tiempo objetivo por medio de la constitución de su objeto y como también acceso a lo universal por medio de la constitución en la conciencia de universalidad (130).

En La idea de la fenomenología, asistimos, entonces, a una minuciosa depuración de lo que es el conocimiento. La pregunta fundamental de la fenomenología tiene que ver con el modo de acceso al conocimiento de las cosas y no a su determinación; y postula que el conocimiento es acto de conocimiento. Los actos de conocimiento son, como el propio Husserl afirma, "correspondencias teleológicas y respectivos nexos de cumplimiento" (135). $Y$ es en relación con estos nexos, con esta trama de actos cognoscitivos de donación, que se constituye la objetualidad de las ciencias objetivas y la realidad efectiva espacio-temporal.

La idea de la fenomenología fue editado por primera vez en 1950 como volumen II de la entonces recién inaugurada serie Husserliana. El texto alemán, fijado por Walter Biemel, ha servido desde su publicación original como texto base desde el cual ha sido vertido a otras lenguas. En castellano, con esta nueva traducción a cargo de Jesús Adrián Escudero, que se suma a la ya existente de Miguel García-Baró de 1982, contamos con dos traducciones completas de La idea de la fenomenología y otras traducciones parciales, pero de escasa circulación académica $y$, por tanto, irrelevantes.

Una lectura comparada del libro aquí reseñado con respecto a las traducciones disponibles (incluyendo a las de otras lenguas) me permite afirmar que estamos ante un gran trabajo editorial y de traducción, altamente meritorio. Si bien con relación a la de Miguel García-Baró (1982) es menos fluida y un poco más difícil de leer, ello se debe a que el traductor parece haberse fijado como criterio seguir estrictamente el ritmo y la cadencia textual de Husserl, lo cual se percibe cuando se coteja con el texto original en lengua alemana. Este detalle, a mi juicio, hace del texto vertido por Jesús Adrián una traducción muy rica técnicamente, bastante precisa en cuanto al léxico $y$, por ello, altamente fiable para usos académicos.

Otros detalles que merecen destacarse de esta nueva traducción: la edición ofrece una traducción completa del aparato crítico de Husserliana II (la de 1982 solo reproduce 
una pequeña proporción); además, el aparato crítico traducido divide las variantes por lecciones $y$, además de que se facilita así la consulta, remite también a la paginación del original alemán, lo que equivale casi a cotejar el texto original. Además, "El curso de las ideas de las lecciones" (Gedankegang der Vorlesungen), que Husserl escribiera la noche de la última sesión a modo de compendio de sus notas, está colocado antes de las Lecciones, por lo que respeta el criterio establecido en el original. Asimismo, la traducción incluye un extenso ensayo introductorio del propio traductor ( $\mathrm{pp}$. 11-56), donde contextualiza los problemas principales abordados por Husserl en La idea de la fenomenología, en tanto que etapa-tránsito entre las Logische Untersuchungen y las Ideen, acompañado de una extensa y útil bibliografía en lengua castellana para quien decida iniciarse en la obra de Husserl. Y finalmente, incorpora al final, como anexos, unas "Notas aclaratorias" que funcionan como una suerte de glosas explicativas de algunos términos empleados por Husserl; un glosario de conceptos clave con su correspondiente traducción; y el índice onomástico recogido en Hua
II con la paginación de la edición alemana.

Sin embargo, se echa en falta las introducciones de Walter Biemel para la primera y segunda ediciones de la Husserliana II; y si bien el criterio de librar al texto original de un aparato de notas que entorpezcan la lectura tiene la virtud (o desventaja, según como se mire) de dejar al lector confrontarse directamente al texto, quizás habría valido la pena incluir algunas aclaraciones en aquellos puntos en los que el propio autor puede resultar un tanto oscuro, para explicar ciertos criterios de traducción o para establecer conexiones con el resto de la obra de Husserl, tal y como incorpora la edición de 1982. Sin embargo, a pesar de estas observaciones, que no desmerecen en absoluto el trabajo realizado por Jesús Adrián, considero que esta nueva traducción viene a aportar un sólido trabajo tanto para los estudiosos de Husserl como para todos aquellos que en el ámbito hispánico deseen adentrarse en los complejos, pero a la vez fascinantes, senderos por los que transita la fenomenología. 